University of Nebraska - Lincoln

DigitalCommons@University of Nebraska - Lincoln

Agronomy \& Horticulture -- Faculty Publications

Agronomy and Horticulture Department

$10-1993$

\title{
An Improved Measure of Angular Dispersion in Plant Neighborhoods
}

Klaus J. Puettmann

University of Minnesota, St. Paul

Dan Rhode

Macalester College

Bruce D. Maxwell

University of Minnesota, St. Paul

John L. Lindquist

University of Nebraska-Lincoln, jlindquist1@unl.edu

Follow this and additional works at: https://digitalcommons.unl.edu/agronomyfacpub

Part of the Plant Sciences Commons

Puettmann, Klaus J.; Rhode, Dan; Maxwell, Bruce D.; and Lindquist, John L., "An Improved Measure of Angular Dispersion in Plant Neighborhoods" (1993). Agronomy \& Horticulture -- Faculty Publications. 379. https://digitalcommons.unl.edu/agronomyfacpub/379

This Article is brought to you for free and open access by the Agronomy and Horticulture Department at DigitalCommons@University of Nebraska - Lincoln. It has been accepted for inclusion in Agronomy \& Horticulture -Faculty Publications by an authorized administrator of DigitalCommons@University of Nebraska - Lincoln. 
Am. Midl. Nat. 130:401-404

\section{An Improved Measure of Angular Dispersion in Plant Neighborhoods}

ABSTRACT.-Spatial distribution is an important factor determining the intensity and outcome of plant competition. The commonly used measure of angular distributions of plants around a target plant $(1-r)$ is shown to be limited to unimodal distributions. We present a new index which is based on the variance of the differences between the azimuth of neighboring plants. The new index is an improvement as it characterizes the angular dispersion in both unimodal and multimodal distributions.

Assessment of spatial arrangement of plants is important for understanding plant interactions. Plant interactions occur when individual plants are close enough to modify their shared environment (Mack and Harper, 1977). Population density by itself does not address the spatial arrangement of individuals, and therefore is an incomplete measure for describing and predicting the behavior of plant populations (Weiner, 1982). The size of a plant has been found to be related to the location of neighboring plants (Mack and Harper, 1977; Weiner, 1982, 1984; Silander and Pacala, 1985; Auld and Tisdell, 1988; Wagner and Radosevich, 1991). Using the neighborhood approach, we note that plant spatial arrangement has been characterized by (1) angular dispersion, the angle between neighbor plants relative to a target plant, and (2) distance dispersion, distance from neighbor plants to a target plant (Mack and Harper, 1977). In this note we indicate shortcomings in the commonly used measure of angular dispersion and present an improved measure.

The most frequently used measure of angular dispersion was introduced to biologists by Zar (1974) and subsequently used by Mack and Harper (1977), Waller (1981), Weiner (1984), Silander and Pacala (1985) and Wagner and Radosevich (1991). Zar's $(1974,1984)$ angular dispersion is expressed as $1-r$, where $r$ is calculated by the formula

$$
r=\sqrt{\left(\frac{\sum_{i=1}^{n} \cos \theta_{i}}{n}\right)^{2}+\left(\frac{\sum_{i=1}^{n} \sin \theta_{i}}{n}\right)^{2}}
$$

where $\theta$ is the azimuth of a neighbor plant location referenced by the target, $\mathrm{n}$ is the total number of neighbor plants, and $i$ is the neighbor plant identifier $(i=1,2, \ldots n)$. [Note that Silander and Pacala 

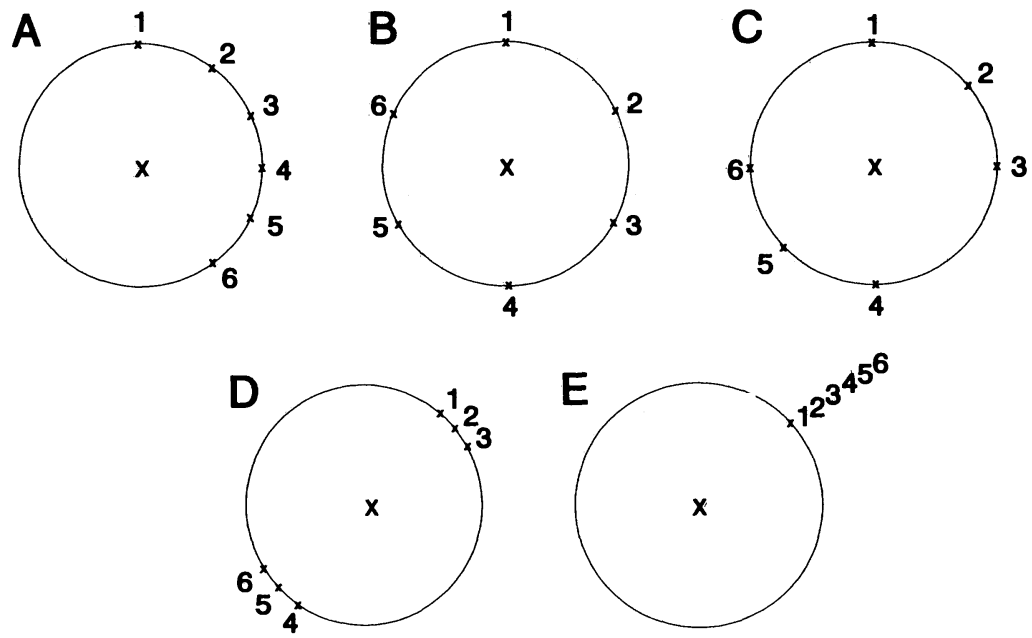

Fig. 1-Examples of unimodal (1A), the most dispersed (1B), bimodal or clumped (1C and 1D), and the most concentrated (1E) angular distributions with six neighbor plants. The azimuth values and dispersion indices are presented in Table 2

(1985) and Wagner and Radosevich (1991) incorrectly replaced the addition sign with a multiplication sign.]

An examination of the formula for $r$ shows that $(1-r)$ together with the mean angle defines the balance point or center of gravity of a circle of neighboring plants (Zar, 1984), but is a true measure of angular dispersion only for unimodal distributions (Zar, 1984). For ease of presentation, we assume that all neighboring plants are located on a circle around the target plant. $r$ is the distance from the center to the balance point of the circle. In unimodal circular distributions, where all neighbor plants are located in one clump (Fig. 1A), the location of the balance point is directly related to the angular dispersion. A balance point far away from the center indicates neighbors concentrated around the circumference of the circle, and a balance point close to the center indicates neighbors dispersed over the circumference. In multimodal distributions, where neighbor plants are located in two or more clumps (Fig. 1C, D), the location of the balance point does not characterize angular dispersion: instead it is related to the symmetry of the clumps around the center (Zar, 1984; Upton and Fingleton, 1989). Upton and Fingleton (1989) modified equation 1 for application to multimodal distributions. However, the modified equation requires that clumps are evenly distributed around the circle, which is a rare case in plant populations. This aspect is important because irregularly spaced clumps of plants are common in plant communities as a result of soil or seed bank heterogeneity or vegetative growth of clonal plants (Kershaw and Looney, 1985).

Using equation 1, both unimodal (Fig. 1B) and multimodal (multiply clumped) (Fig. 1C, D) distributions have $r$ equal to 0 , indicating highest possible dispersion $(1-r=1.0)$. In general, application of equation 1 to distributions will overestimate angular dispersion in neighborhoods where plants are clumped. Auld and Tisdell (1988) have shown that assuming regular spacing in multimodal neighborhoods will underestimate target plant size in yield density models. This bias is confounded with the importance of angular dispersion and might be responsible for the lack of significance of angular dispersion in the work by Weiner (1984) and Wagner and Radosevich (1991).

We suggest an improved measure of angular dispersion, which is not limited to unimodal, or regularly spaced multimodal distributions. Rather than the azimuth itself, the difference between the azimuths of adjacent neighbor plants is used to characterize a distribution. The variance of the differences is then compared to the variance of the most concentrated distribution with the same number of plants (e.g., Fig. 1E). 
TABLE 1.-Predictive equations for angular dispersion (AD) as a function of number of plants (n) for different significance values

\begin{tabular}{ccc}
\hline \hline Significance level & Range of $n$ & \multicolumn{1}{c}{ Equation for prediction of AD } \\
\hline $\mathbf{P}=0.01$ & $10-60$ & $\mathrm{AD}=0.971+0.00059 \mathrm{n}-0.0000046 \mathrm{n}^{2}$ \\
$\mathbf{P}=0.05$ & $5-60$ & $\mathrm{AD}=0.956+0.00115 \mathrm{n}-0.000010 \mathrm{n}^{2}$ \\
$\mathbf{P}=0.10$ & $5-60$ & $\mathrm{AD}=0.940+0.0019 \mathrm{n}-0.000019 \mathrm{n}^{2}$ \\
\hline
\end{tabular}

For calculation purposes the plants are numbered sequentially clockwise, starting with the plant with the smallest azimuth. The angular difference between adjacent plants is calculated as

$$
\alpha_{\mathrm{i}}= \begin{cases}\theta_{\mathrm{i}+1}-\theta_{\mathrm{i}} & \text { for } \mathrm{i}=1,2, \ldots \mathrm{n}-1 \\ 360^{\circ}-\theta_{\mathrm{i}}+\theta_{1} & \text { for } \mathrm{i}=\mathrm{n}\end{cases}
$$

where the variables are as in equation (1) and $\alpha$ is the angular differene between adjacent plants. Note that angular differences are distinct from angular distances (Zar, 1984), since they include a directional component.

Thus, mean angular difference is

$$
\mu=\sum_{\mathrm{i}=1}^{\mathrm{n}-1}\left(\theta_{\mathrm{i}+1}-\theta_{\mathrm{i}}\right)+360^{\circ}-\theta_{\mathrm{i}}+\theta_{1}=\frac{360^{\circ}}{\mathrm{n}}
$$

and the variance of an angular distribution is

$$
\delta=\frac{\sum_{i=1}^{n}\left(\alpha_{i}-\mu\right)^{2}}{n-1}
$$

where the variables are as in equations 1 and $2, \delta$ is the variance.

After calculating $\delta_{t}$ (the variance of a treatment distribution), the same equations (2 through 4) are used to calculate $\delta_{\mathrm{c}}$ (the variance for the most concentrated distribution) in which all points have the same azimuth. The most concentrated distribution has the highest possible variance and to normalize the angular dispersion index (AD), $\mathrm{AD}$ is calculated using the ratio between the two distributions as

$$
\mathrm{AD}=1-\delta_{\mathrm{t}} / \delta_{\mathrm{c}}
$$

The expected value of equation 3 for the most dispersed distribution is 0 , i.e., the expected value for $\mathrm{AD}$ equals 1. Based on the assumption that the azimuths are independently and uniformly distributed, we simulated the distribution of $\mathrm{AD}$ and developed equations for significance testing. Angular dispersion values lower than the values predicted by the equations in Table 1 are significantly

TABLE 2.-Azimuth values and angular dispersion indices for the distributions presented in Figure 1. Angular dispersion was calculated using the traditional method $(1-r)$ and the suggested new $\operatorname{method}_{1}(\mathrm{AD})$

\begin{tabular}{cccccc}
\hline \hline Point & Fig. 1A & Fig. 1B & Fig. 1C & Fig. 1D & Fig. 1E \\
\hline 1 & 0 & 0 & 0 & 35 & 45 \\
2 & 30 & 60 & 45 & 45 & 45 \\
3 & 60 & 120 & 90 & 55 & 45 \\
4 & 90 & 180 & 180 & 215 & 45 \\
5 & 120 & 240 & 225 & 225 & 45 \\
6 & 150 & 300 & 270 & 235 & 45 \\
$1-\mathrm{r}$ & 0.36 & 1 & 1 & 1 & 0 \\
AD & 0.75 & 1 & 0.98 & 0.72 & 0 \\
\hline
\end{tabular}


different from 1, i.e., the plants are not equally spaced around the target plant at the given significance level.

For example, the treatment distribution presented in Figure 1C has a neighbor at the following azimuths: $\theta_{\mathrm{i}}=0^{\circ}, 45^{\circ}, 90^{\circ}, 180^{\circ}, 225^{\circ}$ and $270^{\circ}$ Applying equation 2, the angular differences between neighboring points $\left(\alpha_{\mathrm{i}}\right)$ are $45^{\circ}, 45^{\circ}, 90^{\circ}, 45^{\circ}, 45^{\circ}$ and $90^{\circ}$. Using $\mu=60^{\circ}$ (equation 3 ) and equation 4 leads to a variance $\left(\delta_{t}\right)$ of 540 (degree) $)^{2}$.

The most concentrated distribution with the six neighbor plants (Fig. 1E), has the same $\theta_{\mathrm{i}}$ (in our example $45^{\circ}$ ) for all six points. Using equation 2 the $\alpha_{\mathrm{i}}$ become $0^{\circ}, 0^{\circ}, 0^{\circ}, 0^{\circ}, 0^{\circ}$ and $360^{\circ} . \mu=60^{\circ}$ and application of equation 4 leads to a variance $\left(\delta_{c}\right)$ of 21,600 (degree) $^{2}$. Equation 5 determines the AD value of 0.975 for the distribution in Figure $1 \mathrm{C}$, which is not significantly different from the $\mathrm{AD}$ of a distribution with equally spaced neighbors (Fig. 1B) at $\mathrm{P}=0.05$.

Table 2 presents the angular dispersion values calculated by Zar's $(1974,1984)$ method $(1-r)$ and our method (AD) for the distributions in Figure 1. The comparison of these values shows that $\mathrm{AD}$ is able to distinguish between multimodal distributions which have the same $1-\mathrm{r}$ value. This improvement is important because plants are frequently clumped in natural populations, i.e., have multimodal distributions. We suggest that this improvement will be critical in evaluation of angular dispersion. When all plants are not located the same distance from the target plant, angular dispersion can be combined with distance dispersion (see Mack and Harper, 1977) to a dispersion index. Correct characterization of these components will enhance our understanding of spatial distributions and interactions in plant populations.

Acknowledgments. - The authors acknowledge Hans Weinberger for his suggestion and Jerrold Zar for his thorough review.

\section{Literature Gited}

Auld, B. A. AND C. A. Tisdell. 1988. Influence of spatial distribution on weeds on crop yield loss. Plant Prot. Q., 3:2.

Kershaw, K. A. AND J. H. H. LoONey. 1985. Quantitative and dynamic plant ecology, 3rd ed. Arnold, London. 308 p.

MAGK, R. N. AND J. L. HARPER. 1977. Interference in dune annuals: spatial pattern and neighborhood effects. J. Ecol., 65:345-363.

Silander, J. A. AND S. W. Pacala. 1985. Neighborhood predictors of plant performance. Oecologia (Berl.), 66:256-263.

Upton, G. J. G. AND B. Fingleton. 1989. Spatial data analysis by example. Vol. 2: Categorical and directional data. Wiley and Sons, New York, N.Y. 416 p.

WAGNeR, R. G. AND S. R. RADOSEVICH. 1991. Neighborhood predictors of interspecific competition in young Douglas-fir plantations. Can. J. For. Res., 21:821-828.

Waller, D. M. 1981. Neighborhood competition in several violet populations. Oecologia (Berl.), 51:116-122.

WEINER, J. 1982. A neighborhood model of annual-plant interference. Ecology, 63:1237-1241.

. 1984. Neighborhood interference amongst Pinus rigida individuals. J. Ecol., 72:183-195.

ZAR, J. H. 1974. Biostatistical analysis. Prentice Hall, Englewood Cliffs, N.J. 620 p.

1984. Biostatistical analysis, 2nd ed. Prentice Hall, Englewood Cliffs, N.J. 718 p.

KLAUS J. PUETTMANN, ${ }^{1}$ DAN RHODE, ${ }^{2}$ BRUGE D. MAXWELL ${ }^{3}$ AND JOHN LINDQUIST. ${ }^{3}$ Submitted 8 February 1993; accepted 14 June 1993

\footnotetext{
${ }^{1}$ Department of Forest Resources, University of Minnesota, St. Paul 55108

${ }^{2}$ Macalester College, St. Paul, Minnesota 55104

${ }^{3}$ Department of Agronomy and Plant Genetics, University of Minnesota, St. Paul 55108
} 